bioRxiv preprint first posted online Jan. 31, 2019; doi: http://dx.doi.org/10.1101/535708. The copyright holder for this preprint (which was not peer-reviewed) is the author/funder, who has granted bioRxiv a license to display the preprint in perpetuity.

It is made available under a CC-BY 4.0 International license.

Genotype-phenotype relationships in children with copy number variants associated with high neuropsychiatric risk: Findings from the Intellectual Disability \& Mental Health: Assessing the Genomic Impact on Neurodevelopment (IMAGINE-ID) study.

Samuel J.R.A. Chawner PhDa, Michael J. Owen FRCPsych ${ }^{a}$, Peter Holmans PhDa, Lucy Raymond FRCPb David Skuse MRCPsych ${ }^{c}$, Jeremy Hall MRCPsych ${ }^{\mathrm{a}}$, Marianne B.M. van den Bree PhD ${ }^{1}$ \& IMAGINE-ID Consortium

${ }^{a}$ Medical Research Council Centre for Neuropsychiatric Genetics and Genomics, Division of Psychological Medicine and Clinical Neurosciences, Cardiff University, Cardiff, United Kingdom.

${ }^{\mathrm{b}}$ Department of Medical Genetics, Cambridge Institute for Medical Research, University of Cambridge, Cambridge, UK

${ }^{c}$ Institute of Child Health, University College London, London, UK

${ }^{1}$ these authors contributed equally

Corresponding author: Marianne van den Bree

Email: vandenbreemb@cardiff.ac.uk Phone: +44 (0)29 20688433 Fax: +44(0)29 20687068

Address: Medical Research Council Centre for Neuropsychiatric Genetics and Genomics, $2^{\text {nd }}$ Floor Hadyn Ellis Building, Cardiff University, Maindy Road, Cathays, Cardiff, United Kingdom, CF24 4HQ. 


\begin{abstract}
Background: A variety of copy number variants are associated with a high risk of neurodevelopmental and psychiatric disorders (ND-CNVs). Different ND-CNVs could lead to distinct and specific patterns of cognitive and behavioural outcomes, but supporting evidence is currently lacking.
\end{abstract}

Methods: 258 children with ND-CNVs (13 CNVs across 9 loci) were systematically assessed for psychiatric disorders as well as broader traits of neurodevelopmental, cognitive and psychopathological origin. A comparison was made with 106 non-carrier control siblings, in order to test the hypothesis that phenotypes would differ by genotype, both quantitatively, in terms of severity, and qualitatively in the pattern of associated impairments.

Outcomes: $79.8 \%$ of ND-CNVs carriers met criteria for one or more psychiatric disorders (OR=13.8 compared to controls): the risk of $\operatorname{ADHD}(\mathrm{OR}=6.9), \mathrm{ODD}(\mathrm{OR}=3.6)$, anxiety disorders $(\mathrm{OR}=2.9)$, and ASD traits $(O R=44.1)$ was particularly high. ND-CNVs carriers were impaired across all neurodevelopmental, cognitive, and psychopathological traits relative to controls. Only moderate quantitative and qualitative differences in phenotypic profile were found between genotypes. In general, the range of phenotypes was broadly similar for all ND-CNV genotypes. Traits did show some evidence of genotypic specificity, however the specific genotype accounted for a low proportion of variance in outcome (5-20\% depending on trait).

Interpretation: The 13 ND-CNVs studied have a similar range of adverse effects on childhood neurodevelopment, despite subtle quantitative and qualitative differences. Our findings suggest that genomic risk for neuropsychiatric disorder has pleiotropic effects on multiple processes and neural circuits, and provides important implications for research into genotype-phenotype relationships within psychiatry.

Funding: The Medical Research Council and the Medical Research Foundation 


\section{Research in context}

\section{Evidence before this study}

Several copy number variants (CNVs) have been associated with high risk of development of child and adult neuropsychiatric disorders. Increasingly young children with developmental delay referred for genetic testing are being diagnosed with neurodevelopmental and psychiatric risk CNVs (referred to as ND-CNVs hereafter). It remains unclear whether different genotypes are associated with specific cognitive and behavioural phenotypes or whether these outcomes are non-specific. We searched PubMed for studies published from database inception until January 10th, 2019 that investigated the relationship between CNVs and cognitive and behavioural outcomes. Search terms included "CNV", "genomics", "1q21.1", "2p16.3", "NRXN1", "9q34", "Kleefstra Syndrome", "15q11.2", “15q13.3", "16p11.2", "22q11.2", "psychiatry", and "cognition". Preliminary studies have indicated that deletions and duplications at the same loci may differ in cognitive and behavioural phenotypes. However, to date, there have been limited studies that contrasted the phenotypes of ND-CNVs across several loci on a range of cognitive and behavioural domains.

\section{Added value of this study}

We found that young people carrying a ND-CNV were at considerably increased risk for neuropsychiatric disorder and impairments across a range of neurodevelopmental, psychopathological, cognitive, social, sleep and motor traits. Within ND-CNV carriers, comparisons between genotypes indicated moderate quantitative and qualitative differences in overall phenotypic profile, with evidence that severity of impairment was similar across all genotypes for some traits (e.g. mood problems, sleep impairments, peer problems, and sustained attention) whereas for other traits there was evidence of genotype specific effects on severity (e.g., IQ, spatial planning, processing speed, subclinical psychotic experiences, ASD traits, motor coordination total psychiatric symptomatology, particularly anxiety, ADHD, and conduct related traits). However the proportion of 
bioRxiv preprint first posted online Jan. 31, 2019; doi: http://dx.doi.org/10.1101/535708. The copyright holder for this preprint (which was not peer-reviewed) is the author/funder, who has granted bioRxiv a license to display the preprint in perpetuity. It is made available under a CC-BY 4.0 International license.

variance explained by genotype was low, $5-20 \%$ depending on trait, indicating that overall ND-CNVs lead to similar neurodevelopmental outcomes. It is important that genotype-phenotype relationships are viewed through a developmental lens as some phenotypic outcomes were found to be associated with age.

\section{Implications of all the available evidence}

Children who carry a ND-CNV represent a patient group that warrants clinical and educational attention for a broad range of cognitive and behavioural impairments. Although qualitative and quantitative differences exist between ND-CNVs, our findings point to commonalities in clinical outcomes with neurodevelopmental impairments being present across all ND-CNVs. This group of young people could benefit from the development of a general intervention plan, to which genotype-specific recommendations can be added where needed. Our findings do not support a model whereby different ND-CNVs represent discrete forms of neuropsychiatric disorder and suggest that multiple processes and neural circuits are affected by ND-CNVs. The pleiotropic effects of ND-CNVs emphasises that research aiming to identify causal pathways between genetic variation and psychiatric outcomes via intermediary (or endo-)phenotypes needs to take a global perspective and not be narrowly focused on single phenotypes. 
bioRxiv preprint first posted online Jan. 31, 2019; doi: http://dx.doi.org/10.1101/535708. The copyright holder for this preprint (which was not peer-reviewed) is the author/funder, who has granted bioRxiv a license to display the preprint in perpetuity.

It is made available under a CC-BY 4.0 International license.

\section{Introduction}

The advent of microarray technology has heralded a new era for understanding the clinical genetics of neuropsychiatric disorders. A striking finding has been the implication of copy number variants (CNVs) in these disorders ${ }^{1}$, including intellectual disability (ID), autism spectrum disorder (ASD) and schizophrenia ${ }^{2-4}$. CNVs are submicroscopic deletions or duplications within the genome that are greater than 1000 base pairs ${ }^{5}$ and several loci have been identified whereby CNVs recur with sufficient frequency in the population to be associated with neurodevelopmental and psychiatric outcomes (hereafter referred to as ND-CNVs). Recurrent ND-CNVs are individually rare, but collectively pathogenic ND-CNVs have been implicated in $~ 15 \%$ of patients with neurodevelopmental disability ${ }^{6}$. Although these ND-CNVs are strongly associated with disorder, they have incomplete penetrance and exhibit a high degree of pleiotropy, conferring risk for a broad range of psychiatric disorders, cognitive deficits and medical/physical comorbidities across the lifespan ${ }^{7-10}$.

Current understanding of genotype-phenotype relationships is hampered by a lack of studies that have conducted cross-CNV comparisons ${ }^{11}$. Therefore it is unclear to what extent phenotypic findings for different genotypes can be compared across studies and what the impact is of variation in sample sizes and methodological issues of ascertainment and phenotyping. Increasing use of array screening in the assessment of children with neurodevelopmental delay is leading to a rise in the diagnosis of ND-CNVs by medical genetics clinics, yet information on long-term neuropsychiatric prognosis is lacking. There is a need to understand whether different genotypes are associated with specific neuropsychiatric, cognitive and other phenotypes. We posit four different models of potential genotype-phenotype relationships (Figure 1). 1) The null model proposes that phenotypic profile does not differ between genotypes (Model 1, Figure 1). 2) Phenotypic differences are qualitative in nature, whereby each ND-CNV is associated with a distinct phenotype due to the specific genes involved (Model 2, Figure 1). 3) Phenotypic differences are quantitative in nature whereby all ND-CNVs impact on the same range of outcomes but differ from each other in 
bioRxiv preprint first posted online Jan. 31, 2019; doi: http://dx.doi.org/10.1101/535708. The copyright holder for this preprint (which was not peer-reviewed) is the author/funder, who has granted bioRxiv a license to display the preprint in perpetuity.

It is made available under a CC-BY 4.0 International license.

magnitude of impairment (Model 3, Figure 1). 4) A combination of the Models 2 and 3 best explains differences in phenotypic outcome across ND-CNVs (Model 4, Figure1). There is support for the qualitative differences model in the autism field where it is hypothesised that the disorder is dissociable by the genetic underpinnings ${ }^{12,13}$, with some researchers using the term "autisms" ${ }^{14}$. The quantitative differences model is supported by findings that genes across ND-CNVs impact shared pathways leading to outcomes such as cognitive impairment ${ }^{15}$ and increased schizophrenia risk ${ }^{16}$, indicating that common mechanisms act across loci. It is important to highlight that variability in phenotypic outcomes will also be shaped by incomplete penetrance ${ }^{8}$, life course developmental stage $^{17}$, genetic context including polygenic risk ${ }^{18}$ and additional mutations ${ }^{19,20}$ as well as environmental exposures ${ }^{21}$.

Here we present findings from a cohort of children with ND-CNVs from the IMAGINE-ID (Intellectual Disability \& Mental Health: Assessing the Genomic Impact on Neurodevelopment) consortium. Individuals were recruited on the basis of genotype via the United Kingdom's (UK) National Health Service (NHS) medical genetic clinic network. Broad online phenotyping was conducted on over 2500 individuals (results will be reported elsewhere), and deep phenotyping was conducted within a subgroup of the cohort with assessments covering a range of neuropsychiatric, cognitive and other traits using a multi-informant approach. Here we report on findings from the deep phenotyping component of IMAGINE-ID. First, we characterised the impact of recurrent ND-CNVs on child development by contrasting the performance of CNV carriers with sibling controls. Next, we evaluated the phenotypic differences between genotypes and determined whether these were qualitative or quantitative in nature. Finally, we established the extent to which neuropsychiatric, cognitive and other outcomes are affected by gender and age. 
bioRxiv preprint first posted online Jan. 31, 2019; doi: http://dx.doi.org/10.1101/535708. The copyright holder for this preprint (which was not peer-reviewed) is the author/funder, who has granted bioRxiv a license to display the preprint in perpetuity.

It is made available under a CC-BY 4.0 International license.

\section{Methods}

IMAGINE-ID participants were recruited via the UK NHS medical genetics service, whereby microarray results can be accessed and patients can be retrospectively and prospectively invited to take part in research studies. NHS patients were also recruited via support groups, including Unique, Max Appeal and other groups on social media. Individuals aged 6-19 with CNV at the following loci were approached for deep phenotyping home based assessments; 1q21.1 (proximal and distal), 2p16.3, 9q34, 15q11.2, 15q13.3, 16p11.2 (proximal and distal) and 22q11.2 (Table 1 for further details). These recurrent ND-CNVs were selected because they were robustly associated with ID and neuropsychiatric phenotypes ${ }^{22-24}$, including schizophrenia and ASD, and frequently diagnosed in medical genetic clinics. 274 children with one of these ND-CNVs took part in detailed assessments. 16 were found to have more than one of these ND-CNVs and were excluded from the analysis. This left a sample of 258 children with a ND-CNV (9.7 years (SD=3.1), 65.9\% male) and 106 sibling controls (10.9 years ( $S D=3.0), 51.9 \%$ male). Of the 258 ND-CNV carriers $22.8 \%$ ( $n=59)$ had a de novo variant, $44.2 \%(n=114)$ an inherited variant and for $32.9 \%(n=85)$ the status was unknown. Informed consent was gained from primary carers and participants. Protocols were approved by the NHS London Queen Square research ethics committee. ND-CNV genotype was confirmed via NHS medical genetics clinic records and by the Cardiff University Division of Psychological Medicine and Clinical Neurosciences laboratory.

\section{Assessments}

25 quantitative cognitive and behavioural traits and 5 composite scores were measured using a multi-informant approach. In addition categorical psychiatric diagnoses were derived. Assessments of the child were made by experienced research psychologists. Assessments took place within the participant's home with the advantages this maximised accessibility to the study and reduced bias against participants who may struggle to travel to a research clinic, and furthermore the child could 
bioRxiv preprint first posted online Jan. 31, 2019; doi: http://dx.doi.org/10.1101/535708. The copyright holder for this preprint (which was not peer-reviewed) is the author/funder, who has granted bioRxiv a license to display the preprint in perpetuity.

It is made available under a CC-BY 4.0 International license.

be assessed in a familiar setting where they are less likely to be anxious and more likely to engage with the assessments. Measures are briefly described, full details on assessments and a summary table can be found in the supplementary materials.

\section{Cognition}

Cognition was assessed via direct child assessments. IQ was assessed using the Wechsler Abbreviated Scale of Intelligence (WASI) ${ }^{25}$ from which scores for non-verbal reasoning, perceptual organisation, verbal knowledge and verbal reasoning were derived as well as full scale IQ (FSIQ), performance IQ (PIQ) and verbal IQ (VIQ) composite scores. Set-shifting ability was assessed using the Wisconsin Card Sorting Test (WSCT) ${ }^{26}$. The CANTAB (Cambridge Neuropsychological Test Automated Battery $)^{27}$ was used to assess spatial working memory, spatial planning, sustained attention and processing speed.

Psychopathology and functioning

The Child and Adolescent Psychiatric Assessment (CAPA) ${ }^{28}$ carer report interview was used to derive categorical diagnoses and a total symptom count composite score, as well as the following symptom subscales: attention deficit hyperactivity disorder (ADHD), anxiety, mood, obsessive-compulsive disorder (OCD), oppositional defiant disorder (ODD), and problems with sleep. The child report CAPA was conducted to assess subclinical psychotic experiences. Interviews were taped and diagnoses confirmed in consensus meeting led by a child psychiatrist. General and social functioning was assessed by the psychologists conducting the home visit using the Children's Global Assessment Scale (CGAS) $)^{29}$ and the Social and Occupational Functioning Assessment Scale (SOFAS) ${ }^{30}$. Autism Spectrum Disorder (ASD) traits were assessed via caregiver report using the Social Communication Questionnaire $(\mathrm{SCQ})^{31}$. Motor coordination impairment was assessed via caregiver report using the 
bioRxiv preprint first posted online Jan. 31, 2019; doi: http://dx.doi.org/10.1101/535708. The copyright holder for this preprint (which was not peer-reviewed) is the author/funder, who has granted bioRxiv a license to display the preprint in perpetuity.

It is made available under a CC-BY 4.0 International license.

Developmental Coordination Disorder Questionnaire (DCDQ) $)^{32}$. The Strengths and Difficulties Questionnaire $(\mathrm{SDQ})^{33}$ was completed by the caregiver and the teacher from which conduct, emotional, hyperactivity, peer (quality of peer relationships) and prosocial subscale scores were derived as well as SDQ total composite score.

\section{Analysis}

Aim 1: Cognitive and behavioural phenotype of ND-CNV carriers in relation to controls

\section{Categorical outcome measures}

The prevalence of psychiatric disorder was compared between ND-CNV carriers and controls.

Analysis was conducted using generalized linear mixed-effects models, with carrier status, age and gender as fixed effects and family as a random effect to take into account that control siblings are related to ND-CNV carriers.

\section{Continuous outcome measures}

All cognitive and behavioural trait scores and composite scores (FSIQ, PIQ, VIQ, total symptom count and SDQ total score) were transformed using Tukey's Ladder of Powers. This transformation makes the data fit the normal distribution as closely as possible. All tests scores were then standardised into z-scores using the mean and SDs of the control group as reference. Z-scores were constructed so that a negative score denoted a poorer outcome. Linear mixed-effects models were conducted with test score as the outcome and carrier status, age and gender as fixed effects and family as a random effect. To estimate the standardised difference between ND-CNV carriers and controls Cohen's $d$ was calculated. To assess the potential effects of intelligence on group differences, analyses were repeated with FSIQ as a covariate. To correct for multiple testing in Aim 1 a Benjamini-Hochberg false discovery rate (B-H FDR) of 0.05 for correction of $p$-values was applied. 
bioRxiv preprint first posted online Jan. 31, 2019; doi: http://dx.doi.org/10.1101/535708. The copyright holder for this preprint (which was not peer-reviewed) is the author/funder, who has granted bioRxiv a license to display the preprint in perpetuity.

It is made available under a CC-BY 4.0 International license.

To investigate which genotype-phenotype relationship model (Figure 1) best explained our data, we first calculated the mean z-score for each ND-CNV on each trait, with each score representing the difference of each ND-CNV relative to the control group, adjusted for age and gender. Hierarchical clustering was performed using Ward's method and Euclidian distance to investigate which NDCNVs, and which cognitive and behavioural phenotypes clustered together.

Analysis of qualitative and quantitative differences in overall phenotypic profile was based on ranking the mean of each phenotypic trait score for each ND-CNV. In the analysis of qualitative effects a set of phenotype rankings was created for each ND-CNV (Model 2, Figure 1, within each genotype row, phenotype was ranked by phenotypic severity). Rank discordance between ND-CNVs would suggest that the phenotype profile for each ND-CNV differs, therefore indicating the presence of qualitative differences. In the analysis of quantitative effects a set of ND-CNV rankings was created for each phenotype (Model 3, Figure 1, within each phenotype column, each ND-CNV was ranked by phenotypic severity). Rank concordance between phenotypes would suggest that ND-CNVs differ in severity across phenotypes, therefore indicating quantitative differences. Note these models aren't opposing ends of a spectrum, both quantitative and qualitative effects can be present (Model 4, Figure 1). To test for similarities and differences for both qualitative and quantitative effects across ND-CNVs, rank concordance was assessed using Kendall's test and rank discordance using the Friedman test. This rank concordance based approach has been previously used to investigate genotype-phenotype relationships ${ }^{34}$. To avoid collinearity, composite scores were not included in the concordance analysis. Furthermore to test for quantitative effects between ND-CNVs at the level of individual traits, ANCOVAs were conducted with the test score as the outcome, genotype as the predictor, and gender and age as covariates. To correct for multiple testing a B-H FDR 0.05 correction of $p$-values was applied.

\section{Aim 3: Effect of age and gender on cognitive and behavioural outcomes}

To investigate the influence of gender and age on the outcomes within ND-CNV carriers, we estimated eta-squared and standardised beta value from the ANCOVAs conducted for the quantitative analysis. 
bioRxiv preprint first posted online Jan. 31, 2019; doi: http://dx.doi.org/10.1101/535708. The copyright holder for this preprint (which was not peer-reviewed) is the author/funder, who has granted bioRxiv a license to display the preprint in perpetuity.

It is made available under a CC-BY 4.0 International license.

Eta-squared values reflect the proportion of variance in the quantitative trait explained by the predictor and the standardised beta values reflect the magnitude and direction of effect of the predictor on phenotypic outcome. To correct for multiple testing B-H FDR 0.05 correction of p-values was applied.

\section{Role of the funding source}

The funders of the study had no role in study design, data collection, data analysis, data interpretation, or writing of the report. The corresponding author had full access to all the data in the study and had final responsibility for the decision to submit for publication.

\section{Results}

Aim 1:

Cognitive and behavioural phenotype of ND-CNV carriers in relation to controls

\section{Categorical outcome measures}

Prevalence of psychiatric disorder was significantly elevated in ND-CNV carriers (79.8\%) compared to controls $\left.(21.3 \%), \mathrm{OR}=13.8,95 \% \mathrm{Cl}=7.2-26.3, \mathrm{p}=7.79 \times 10^{-7}\right)$. ND-CNV carriers had significantly elevated rates of $\operatorname{ADHD}\left(47.2 \%\right.$ vs $\left.11.0 \%, \mathrm{OR}=6.9,95 \% \mathrm{Cl}=3.2-15.1,2.09 \times 10^{-6}\right)$, ODD $(20.6 \%$ vs $6.7 \%$, $\left.\mathrm{OR}=3.6,95 \% \mathrm{Cl}=1.4-9.4, \mathrm{p}=1.20 \times 10^{-2}\right)$, anxiety disorder $(21.9 \%$ vs $9.3 \%, \mathrm{OR}=2.9,95 \% \mathrm{Cl}=1.2-6.7$, $\left.p=1.46 \times 10^{-2}\right), \operatorname{ASD}\left(66.1 \%\right.$ vs $\left.4.7 \%, O R=44.1,95 \% \mathrm{Cl}=15.3-127.5,2.50 \times 10^{-9}\right)$ and Tic Disorder $(16.3 \%$ vs $0.0 \%, p=2.10 \times 10^{-5}$, OR could not be estimated as no controls affected) compared to controls (see Table 2). These results remained significant when FSIQ was controlled for, and all survived B-H FDR correction. Mood disorder, OCD and subclinical psychotic experiences were present in ND-CNV carriers but prevalence was not significantly elevated relative to controls. None of the ND-CNV carriers or controls met criteria for psychotic disorder. 
bioRxiv preprint first posted online Jan. 31, 2019; doi: http://dx.doi.org/10.1101/535708. The copyright holder for this preprint (which was not peer-reviewed) is the author/funder, who has granted bioRxiv a license to display the preprint in perpetuity.

It is made available under a CC-BY 4.0 International license.

\section{Continuous outcome measures}

Linear mixed-effects model analysis found that ND-CNV carriers showed significant impairment on all cognitive and behavioural traits and composite scores (Table 3, Figure 2) compared to controls. These results remained significant when FSIQ was controlled for, and all survived B-H FDR correction. Cohen's d varied from 0.27 (subclinical psychotic experiences) to 1.76 (hyperactivity subscale, caregiver reported). Large effect size differences between ND-CNV carriers and controls were found for FSIQ, including PIQ, VIQ and all comprising subtests, sustained attention, total psychiatric symptom count, ADHD and ASD traits, motor coordination, general and social functioning, total SDQ score (carer and teacher report) and hyperactivity (carer and teacher report), peer (carer report), prosocial (carer report) SDQ subscales.

As well as caregiver report, teachers reported that ND-CNV carriers scored significantly worse on SDQ total score and subscale scores (Table 3 and Figure 2). Teacher reported SDQ scores were moderately correlated with carer report scores; total SDQ score $r=0.470, p=1.35 \times 10^{-11}$; SDQ subscale scores, $r=$ 0.316 to $0.548, p=5.69 \times 10^{-16}$ to $1.13 \times 10^{-5}$.

\section{Aim 2: Qualitative and quantitative differences between genotypes}

Mean performance (adjusted for age and gender) on phenotypic traits for each ND-CNV are visualised in Figure 3, where distinct profiles are apparent. Regarding phenotypic associations, 2 clusters can be distinguished; neurodevelopmental traits (Figure 3, Box B); and mental health and cognitive comorbidities (Figure 3, Box A). All genotypes showed evidence of strong impairments in the neurodevelopmental traits cluster, whereas level of impairment within the mental health and cognitive comorbidities cluster was less and more variable across ND-CNVs. The dendrogram on Figure 3 shows the pattern of ND-CNV clustering, there was no strong evidence that deletion variants differed in profile from duplication variants, or that deletions and duplications at the same loci differed in profile. 
bioRxiv preprint first posted online Jan. 31, 2019; doi: http://dx.doi.org/10.1101/535708. The copyright holder for this preprint (which was not peer-reviewed) is the author/funder, who has granted bioRxiv a license to display the preprint in perpetuity.

It is made available under a CC-BY 4.0 International license.

In terms of the overall phenotypic profile there was evidence of both qualitative and quantitative differences between genotypes. Both tests of significance for rank concordance and discordance were significant for both analyses of qualitative (Friedman chi-squared $=177.39, p<1.00 \times 10^{-15}$; Kendall $F=15.81, p<1.00 \times 10^{-15}$ ) and quantitative effects (Friedman chi-squared $=53.04, p=4.06 \times 10^{-7}$; Kendall $\left.F=5.15, p<8.72 \times 10^{-8}\right)$. These findings indicate that, although significant quantitative and qualitative differences exist, the converse is true in that qualitative and quantitative similarities also exist. We therefore conclude effects for both qualitative as well as quantitative differences between genotypes are moderate, and overall our data supports Model 4 (Figure 1). A sensitivity analysis was conducted excluding individuals with 9q34.3 deletion or 22q11.2 deletion as the dendrogram (Figure 3) indicated their phenotypic profiles stood apart from the other ND-CNVs and that this could drive the differences we found. However, excluding these two groups did not change our finding of moderate qualitative and a quantitative differences between genotypes, and did not change the hierarchical clustering of traits into neurodevelopmental traits and mental health and cognitive comorbidities.

At the level of individual phenotypic traits quantitative differences were found with genotype predicting between $5-20 \%$ of variance (Eta-squared effect size) in impairment within ND-CNV carriers depending on the specific trait (Table 4). The effect of genotype significantly predicted impairment severity in some traits; $\mathrm{FSIQ}, \mathrm{PIQ}, \mathrm{VIQ}$, all the IQ subtests, spatial planning, processing speed, total CAPA symptom count including the anxiety, ADHD and ODD subscales, subclinical psychotic experiences, social functioning, ASD traits, motor coordination, SDQ total including conduct, hyperactivity and prosocial subscales (Table 4). However, for set-shifting ability, spatial working memory, sustained attention, mood CAPA subscale, OCD CAPA subscale, sleep CAPA subscale, general functioning, emotional SDQ subscale, and the peer SDQ subscale, the effect of genotype was not significant. For these analyses, $p$-values equal or less than 0.02 survived BH-FDR 0.05 correction. 
bioRxiv preprint first posted online Jan. 31, 2019; doi: http://dx.doi.org/10.1101/535708. The copyright holder for this preprint (which was not peer-reviewed) is the author/funder, who has granted bioRxiv a license to display the preprint in perpetuity.

It is made available under a CC-BY 4.0 International license.

\section{Aim 3: Effect of age and gender on cognitive and behavioural outcomes}

The phenotypic profile of ND-CNV carriers was influenced by age (accounting for $0-25 \%$ of variance depending on trait) with deficits in some traits becoming reduced in older children: the hyperactivity SDQ subscale $\left(\beta=0.18, p=5.04 \times 10^{-3}\right)$, sustained attention $\left(\beta=0.53, p=1.89 \times 10^{-11}\right.$ and higher executive function (set-shifting, $\beta=0.18, p=1.32 \times 10^{-2}$ ). Deficits in other traits were found to be greater in older children; FSIQ $\left(\beta=-0.18, p=3.61 \times 10^{-3}\right)$, spatial working memory $\left(\beta=-0.10, p=7.92 \times 10^{-}\right.$ $\left.{ }^{3}\right)$, mood CAPA subscale $\left(\beta=-0.17, p=1.05 \times 10^{-2}\right)$, subclinical psychotic experiences $(\beta=-0.20$, $\left.p=1.40 \times 10^{-3}\right)$, and the peer subscale of the SDQ $\left(\beta=-0.21, p=1.34 \times 10^{-3}\right)$. Gender was found to influence phenotypic outcomes in ND-CNV carriers, but accounted for little variation (0-4\% depending on trait). Males had greater deficits on the hyperactivity SDQ subscale ( $\beta=0.17$, $\left.p=1.61 \times 10^{-2}\right)$, sleep CAPA subscale $\left(\beta=0.16, p=1.83 \times 10^{-2}\right)$ and sustained attention $(\beta=0.18$, $\left.p=5.35 \times 10^{-3}\right)$ than females, but they performed better on the PIQ perceptual organisation subtest $(\beta$ $\left.=-0.16, p=6.37 \times 10^{-3}\right)$. For these analyses, $p$-values equal or less than 0.02 survived $B H-F D R 0.05$ correction.

\section{Discussion}

The IMAGINE-ID cohort allowed us to conduct one of the largest studies to define genotypephenotype relationships across a range of ND-CNV loci. Overall our findings support a model whereby these ND-CNVs have a broadly general effect on phenotypic outcome, but specific effects can be identified, albeit accounting for a low proportion of variance ( $5-20 \%$ depending on trait). Some traits had similar levels of impairment across all genotypes (e.g. mood problems, sleep impairments, peer problems, and sustained attention) whereas for other traits there was more evidence of genotype specific patterns (e.g., IQ, spatial planning, processing speed, subclinical psychotic experiences, ASD traits, motor coordination total psychiatric symptomatology, particularly anxiety, ADHD, and conduct related traits). Phenotypic differences between ND-CNVs were found to be both quantitative and as well as qualitative in nature (Model 4, Figure 1). Hierarchical cluster analysis of phenotypic traits 
bioRxiv preprint first posted online Jan. 31, 2019; doi: http://dx.doi.org/10.1101/535708. The copyright holder for this preprint (which was not peer-reviewed) is the author/funder, who has granted bioRxiv a license to display the preprint in perpetuity.

It is made available under a CC-BY 4.0 International license.

identified two clusters; neurodevelopmental traits that were strongly impaired across CNVs, and mental health and cognitive comorbidities where impairment was generally less and more variable across the genotypes. ND-CNVs affect biological pathways that impact risk of developmental impairment and this impairment differs in magnitude by genotype, but the unique gene content of each ND-CNV also appears to mould the specific psychiatric, cognitive and other manifestations. As a group, children with a ND-CNV were found to be at very high risk of developing psychiatric disorder, with $79.8 \%$ having at least one psychiatric diagnosis. Moreover, using a broad multi-informant approach we found that ND-CNV carriers were impaired relative to their siblings across all the psychiatric, neurodevelopmental, psychopathological, cognitive, social, sleep and motor domains assessed. This patient group clearly warrants clinical and educational attention and intervention.

ND-CNV carriers were found to be at increased risk for a range of psychiatric disorders $(O R=13.8$ for any disorder), including $A D H D(O R=6.9)$, anxiety disorder ( $O R=2.9), A S D(O R=44.1), O D D(O R=43.6)$, and tic disorders (OR could not be calculated as no controls were affected). All the ND-CNV carriers were impaired across all behavioural and cognitive traits measured, the strongest trait differences found between ND-CNV carriers and controls included ASD symptom count ( $d=1.71$ ), hyperactivity $(d=1.76)$, social functioning $(d=1.60)$ and motor coordination $(d=1.62)$. Motor coordination is a domain that has been relatively understudied in the context of ND-CNV carriers, but recent studies indicate that it is an antecedent ${ }^{35}$ of, and indexes, psychiatric disorder ${ }^{36}$ in ND-CNV carriers. Our teacher-report measures confirmed that neuropsychiatric impairments were present in multiple settings, indicating pervasiveness. Our findings of broad ranging impairments is consistent with studies of common polygenic risk ${ }^{37}$ and familial risk ${ }^{38,39}$ of psychiatric disorder, that find that genetic risk is associated with disrupted childhood neurodevelopment across several domains.

Strikingly, the specific effect of CNV genotype only accounted for $5-20 \%$ of variation in outcome depending on phenotypic trait, indicating that the majority of variance is explained by additional factors. We found that age was a predictor of outcome for several traits, both ADHD symptoms and 
bioRxiv preprint first posted online Jan. 31, 2019; doi: http://dx.doi.org/10.1101/535708. The copyright holder for this preprint (which was not peer-reviewed) is the author/funder, who has granted bioRxiv a license to display the preprint in perpetuity.

It is made available under a CC-BY 4.0 International license.

deficits in our cognitive measures of sustained attention and executive function decreased with age, whereas IQ deficits, spatial working memory, mood symptoms, subclinical psychotic experiences and peer problems increased with age. These findings illustrate the importance of viewing genotypephenotype relationships through a developmental lens ${ }^{17,40}$ and warrant future longitudinal studies. We also found that gender predicts outcome for ADHD related traits, however the effect sizes were small with gender accounting for $<5 \%$ of the explained variance. A lack of strong gender differences in neurodevelopmental traits may reflect that male-to-female ratios for conditions such as autism are reduced in populations with intellectual disability ${ }^{41}$. Further research will be required to understand what genetic and environmental factors underlie the remaining, unexplained variation, in outcome.

The high prevalence of psychiatric disorders and the finding that ND-CNV carriers were impaired across all the cognitive, motor and psychopathological measures assessed highlight that children with ND-CNVs require coordinated multidisciplinary care to address a range of psychiatric, psychological, motor coordination, sleep and social and educational needs. This warrants a step change in current clinical service provision, and calls for greater awareness of this new patient group amongst clinicians and educators. The commonalities we are finding in clinical outcomes across all ND-CNVs suggest this group could benefit from the development of a general intervention plan, which could be expanded to include specific recommendations for more genotype-specific outcomes. Support and intervention plans for children with a ND-CNV need to consider the child's behaviour in educational and peer contexts as well as address behaviour exhibited in the home or clinic. The broad ranging phenotypic outcomes associated with ND-CNVs indicates that genotype-phenotype relationships have a complex architecture. Current research efforts that use genetic first approaches in human studies and animal models as a way of identifying direct causal pathways from genotype to psychiatric disorder via intermediary phenotypes need to take account of these complexities, the use of an endophenotype approach should be cautioned ${ }^{42}$. Systems biology and network approaches are needed to globally capture the architecture of genotype-phenotype relationships. Efforts focusing on single causal pathways are likely to only provide limited research and clinical benefit. 


\section{Limitations}

Individuals had to have a known genetic diagnosis to take part, the study would therefore not capture asymptomatic individuals who carry ND-CNVs. Therefore, the true phenotype in the general population is likely to be less severe than what we report, with bias being greater for those ND-CNVs with a lower penetrance. However, it is important to put our study in context with wider research. Large population-based studies have examined the phenotype of ND-CNVs in adults from the general population ${ }^{7,9}$, but the present study gives unique insights into the development of children at the more severe end of the phenotypic spectrum who are most likely to engage with health services and be in need of clinical and educational support. Some of our findings could reflect ascertainment bias, in that carriers with severe developmental delay are more likely to be referred to medical genetic clinics for testing. However, we found that the differences between ND-CNV carriers and controls remained significant after controlling for IQ.

\section{Conclusion}

Our findings provide evidence of specific genotype-phenotype relationships within CNV carriers both in terms of quantitative and qualitative differences. However, although differences can be identified, these account for a low proportion of variance and therefore we conclude that different genotypes do not result in discrete forms of neurodevelopmental disorders. Our dimensional approach facilitated the investigation of genotype-phenotype relationships beyond categorical psychiatric diagnosis. Using a multi-informant deep phenotyping approach we found that genomic risk for psychiatric disorder had wide ranging effects on childhood development spanning a range of cognitive and behavioural domains. Our findings highlight that there are core neurodevelopmental traits that are strongly impaired across all ND-CNV carriers, but additionally ND-CNV carriers are also affected by there are broad-ranging mental health and cognitive comorbidities. This suggests that multiple processes and neural circuits are affected by ND-CNVS. Future research into the relationship between genotype and psychiatric outcomes via intermediary endophenotypes needs 
bioRxiv preprint first posted online Jan. 31, 2019; doi: http://dx.doi.org/10.1101/535708. The copyright holder for this preprint (which was not peer-reviewed) is the author/funder, who has granted bioRxiv a license to display the preprint in perpetuity.

It is made available under a CC-BY 4.0 International license.

to consider this when interpreting findings. Early detection of children with ND-CNVs is warranted to a) investigate antecedents and developmental course of neuropsychiatric impairments, b) add to the understanding of how genomic risk manifests, c) inform early intervention programs. 
bioRxiv preprint first posted online Jan. 31, 2019; doi: http://dx.doi.org/10.1101/535708. The copyright holder for this preprint (which was not peer-reviewed) is the author/funder, who has granted bioRxiv a license to display the preprint in perpetuity.

It is made available under a CC-BY 4.0 International license.

\section{Acknowledgements}

We would like to thank all the children, families and teachers who took part in the IMAGINE-ID study, as well as all the support we have had from NHS medical genetic clinics, and support charities including Unique and Max Appeal. We thank all members of the IMAGINE-ID consortium for their contributions. We thank Matthew Sopp, Alice Robinson, Sinéad Ray, Nicola Lewis, Sarah Law, Sophie Andrews, Aimée Davies, Poppy Sloane, Alice Walsh, Keziah Fish, Amy Ilsley, Stephen Naughton, Rachel Tompkins, Ciara Walker, Nadia Pantouw, Samantha Bowen, Hannah Pendlebury, Chloe Sheldon, Emily Green, Umaya Prasad, Joshua Roberts, Jessica Townsend and Beth Hughes for their roles in data collection. We thank Nigel Williams, Andrew Cuthbert and Alexandra Evans for their support in interpreting genotype information, Hayley Moss for research management support and Karen Bradley for administrative support. We thank the core laboratory team of the Division of Psychological Medicine and Clinical Neurosciences laboratory for DNA sample management and genotyping. We also thank the National Centre for Mental Health, a collaboration between Cardiff, Swansea and Bangor Universities, for their support.

This work was funded by Medical Research Council grants MR/L011166/1 and MR/N022572/1.

\section{Conflict of interests}

MJ Owen, J Hall, P Holmans and MBM van den Bree are supported by a collaborative research grant from Takeda. Takeda played no part in the conception, design, implementation, or interpretation of this study, which was completed prior to the funding award. 


\section{References}

1. Morrow EM. Genomic copy number variation in disorders of cognitive development. Journal of the American Academy of Child \& Adolescent Psychiatry 2010; 49(11): 1091-104.

2. Rees $\mathrm{E}$, Kendall K, Pardiñas AF, et al. Analysis of intellectual disability copy number variants for association with schizophrenia. JAMA psychiatry 2016; 73(9): 963-9.

3. Malhotra D, Sebat J. CNVs: Harbingers of a Rare Variant Revolution in Psychiatric Genetics. Cell 2012; 148(6): 1223-41.

4. Sanders SJ, He X, Willsey AJ, et al. Insights into autism spectrum disorder genomic architecture and biology from 71 risk loci. Neuron 2015; 87(6): 1215-33.

5. Lee $\mathrm{C}$, Scherer SW. The clinical context of copy number variation in the human genome. Expert reviews in molecular medicine 2010; 12: e8.

6. Miller DT, Adam MP, Aradhya S, et al. Consensus statement: chromosomal microarray is a first-tier clinical diagnostic test for individuals with developmental disabilities or congenital anomalies. The American Journal of Human Genetics 2010; 86(5): 749-64.

7. Kendall KM, Rees E, Escott-Price V, et al. Cognitive performance among carriers of pathogenic copy number variants: analysis of 152,000 UK biobank subjects. Biological psychiatry 2017; 82(2): 103-10.

8. Kirov $G$, Rees $E$, Walters J. What a psychiatrist needs to know about copy number variants. Advances in Psychiatric Treatment 2015; 21(3): 157-63.

9. Stefansson $\mathrm{H}$, Meyer-Lindenberg A, Steinberg S, et al. CNVs conferring risk of autism or schizophrenia affect cognition in controls. Nature 2014; 505(7483): 361-6.

10. Niarchou M, Zammit S, van Goozen SHM, et al. Psychopathology and cognition in children with 22q11.2 deletion syndrome. British Journal of Psychiatry 2014; 204(1): 46-54.

11. Bishop SL, Farmer C, Bal V, et al. Identification of developmental and behavioral markers associated with genetic abnormalities in autism spectrum disorder. American Journal of Psychiatry 2017; 174(6): 576-85.

12. Ronald A, Happe F, Bolton P, et al. Genetic heterogeneity between the three components of the autism spectrum: a twin study. Journal of the American Academy of Child \& Adolescent Psychiatry 2006; 45(6): 691-9.

13. Bruining H, Eijkemans MJ, Kas MJ, Curran SR, Vorstman JA, Bolton PF. Behavioral signatures related to genetic disorders in autism. Molecular autism 2014; 5(1): 1.

14. Geschwind DH, Levitt P. Autism spectrum disorders: developmental disconnection syndromes. Current opinion in neurobiology 2007; 17(1): 103-11.

15. Huguet G, Schramm C, Douard E, et al. Measuring and Estimating the Effect Sizes of Copy Number Variants on General Intelligence in Community-Based Samples. JAMA psychiatry 2018.

16. Pocklington AJ, Rees E, Walters JT, et al. Novel findings from CNVs implicate inhibitory and excitatory signaling complexes in schizophrenia. Neuron 2015; 86(5): 1203-14.

17. Chawner SJ, Doherty JL, Moss H, et al. Childhood cognitive development in 22q11. 2 deletion syndrome: case-control study. The British Journal of Psychiatry 2017: bjp. bp. 116.195651.

18. Tansey $\mathrm{K}$, Rees $\mathrm{E}$, Linden $\mathrm{D}$, et al. Common alleles contribute to schizophrenia in CNV carriers. Molecular psychiatry 2016; 21(8): 1085.

19. D'Angelo D, Lebon $S$, Chen $Q$, et al. Defining the effect of the $16 \mathrm{p} 11.2$ duplication on cognition, behavior, and medical comorbidities. JAMA psychiatry 2016; 73(1): 20-30.

20. Bassett AS, Lowther C, Merico D, et al. Rare genome-wide copy number variation and expression of schizophrenia in 22q11. 2 deletion syndrome. American Journal of Psychiatry 2017; 174(11): 1054-63.

21. Kates W, Russo N, Wood W, Antshel K, Faraone S, Fremont W. Neurocognitive and familial moderators of psychiatric risk in velocardiofacial (22q11. 2 deletion) syndrome: a longitudinal study. Psychological medicine 2014: 1-11. 
bioRxiv preprint first posted online Jan. 31, 2019; doi: http://dx.doi.org/10.1101/535708. The copyright holder for this preprint (which was not peer-reviewed) is the author/funder, who has granted bioRxiv a license to display the preprint in perpetuity. It is made available under a CC-BY 4.0 International license.

22. Rees E, Walters JT, Georgieva L, et al. Analysis of copy number variations at 15 schizophrenia-associated loci. The British journal of psychiatry : the journal of mental science 2014; 204(2): 108-14.

23. Doherty JL, Owen MJ. Genomic insights into the overlap between psychiatric disorders: implications for research and clinical practice. Genome Med 2014; 6(4): 29.

24. Coe BP, Witherspoon $\mathrm{K}$, Rosenfeld JA, et al. Refining analyses of copy number variation identifies specific genes associated with developmental delay. Nature genetics 2014; 46(10): 1063. 25. Wechsler D. Manual for the Wechsler abbreviated intelligence scale (WASI); 1999.

26. Heaton R, Chelune G, Talley J, Kay G, Curtiss G. Wisconsin card sorting test manual revised and expanded. Lutz, FL: Psychological Assessment Resources. Inc; 1993.

27. CANTAB. CANTAB eclipse version 3. Cambridge: Cambridge Cognition; 2006.

28. Angold A, Prendergast M, Cox A, Harrington R, Simonoff E, Rutter M. The child and adolescent psychiatric assessment (CAPA). Psychological medicine 1995; 25(04): 739-53.

29. Shaffer D, Gould MS, Brasic J, et al. A children's global assessment scale (CGAS). Archives of General psychiatry 1983; 40(11): 1228-31.

30. Morosini PL, Magliano L, Brambilla L, Ugolini S, Pioli R. Development, reliability and acceptability of a new version of the DSM-IV Social and Occupational Functioning Assessment Scale (SOFAS) to assess routine social funtioning. Acta Psychiatrica Scandinavica 2000; 101(4): 323-9.

31. Rutter M, Bailey A, Lord C. The social communication questionnaire: Manual: Western Psychological Services; 2003.

32. Wilson BN, Crawford SG, Green D, Roberts G, Aylott A, Kaplan BJ. Psychometric properties of the revised Developmental Coordination Disorder Questionnaire. Physical \& occupational therapy in pediatrics 2009; 29(2): 182-202.

33. Goodman R. The Strengths and Difficulties Questionnaire: a research note. Journal of child psychology and psychiatry, and allied disciplines 1997; 38(5): 581-6.

34. Hühn M, Piepho H. Relationships between Kendall's coefficient of concordance and a nonparametric measure of phenotypic stability with implications for the consistency in rankings as affected by variance components. Biometrical journal 1994; 36(6): 719-27.

35. Bernier R, Hudac CM, Chen $Q$, et al. Developmental trajectories for young children with 16p11. 2 copy number variation. American Journal of Medical Genetics Part B: Neuropsychiatric Genetics 2017; 174(4): 367-80.

36. Cunningham AC, Delport S, Cumines W, et al. Developmental coordination disorder, psychopathology and IQ in 22q11. 2 deletion syndrome. The British Journal of Psychiatry 2018; 212(1): 27-33.

37. Riglin L, Collishaw S, Richards A, et al. Schizophrenia risk alleles and neurodevelopmental outcomes in childhood: a population-based cohort study. The Lancet Psychiatry 2017; 4(1): 57-62.

38. Burton BK, Vangkilde S, Petersen A, et al. Sustained Attention and Interference Control among 7-year-old Children with a Familial High Risk of Schizophrenia or Bipolar Disorder-a Nationwide Observational Cohort Study. Biological Psychiatry: Cognitive Neuroscience and Neuroimaging 2018.

39. Ellersgaard D, Jessica Plessen K, Richardt Jepsen J, et al. Psychopathology in 7-year-old children with familial high risk of developing schizophrenia spectrum psychosis or bipolar disorderThe Danish High Risk and Resilience Study-VIA 7, a population-based cohort study. World Psychiatry 2018; 17(2): 210-9.

40. Hall J, Owen MJ. Psychiatric classification-a developmental perspective. The British Journal of Psychiatry 2015; 207(4): 281-2.

41. Newschaffer CJ, Croen LA, Daniels J, et al. The epidemiology of autism spectrum disorders*. Annu Rev Public Health 2007; 28: 235-58.

42. Walters J, Owen M. Endophenotypes in psychiatric genetics. Molecular psychiatry 2007; 12(10): 886-90. 


\begin{tabular}{|c|c|c|c|c|}
\hline ND-CNV & Locus & $\begin{array}{l}\text { Critical/Unique Sequence Region } \\
\text { (hg19) }\end{array}$ & $\begin{array}{l}\text { Gene/Locus } \\
\text { MIM } \\
\text { number }\end{array}$ & $\mathbf{N}$ \\
\hline 1q21.1 proximal duplication & $1 \mathrm{q} 21.1$ & chr1:145,394,955-145,807,817 & $\#$ & 14 \\
\hline 1q21.1 distal deletion & 1q21.1 & chr1:146,527,987-147,394,444 & 612474 & 21 \\
\hline 1q21.1 distal duplication & 1q21.1 & chr1:146,527,987-147,394,444 & 612475 & 21 \\
\hline 2p16.3 deletion (NRXN1) & $2 p 16.3$ & chr2:50145643-51259674 & 600565 & 14 \\
\hline 9q34 del (Kleefstra, EHMT1) & $9 q 34.4$ & chr9:140,513,444-140,730,578 & 607001 & 10 \\
\hline 15q11.2 deletion BP1-BP2 & $15 q 11.2$ & chr15:22,805,313-23,094,530 & 615656 & 35 \\
\hline 15q13.3 deletion (CHRNA7) & $15 q 13.3$ & chr15:32,017,070-32,453,068 & 612001 & 20 \\
\hline 15q13.3 duplication (CHRNA7) & $15 q 13.3$ & chr15:32,017,070-32,453,068 & $\#$ & 12 \\
\hline 16p11.2 distal deletion (220kb) & $16 p 11.2$ & chr16:28,823,196-29,046,783 & 613444 & 12 \\
\hline 16p11.2 proximal deletion (593kb) & $16 \mathrm{p} 11.2$ & chr16:29,650,840-30,200,773 & 611913 & 44 \\
\hline 16p11.2 proximal duplication (593kb) & $16 \mathrm{p} 11.2$ & chr16:29,650,840-30,200,773 & 614671 & 19 \\
\hline 22q11.2 deletion (VCFS/DiGeorge) & $22 q 11.2$ & chr22:19,037,332-21,466,726 & 602054 & 17 \\
\hline 22q11.2 duplication & $22 q 11.2$ & chr22:19,037,332-21,466,726 & 608363 & 19 \\
\hline
\end{tabular}

\# Not listed on Mendelian Inheritance in Man (MIM) website but associated with neurodevelopmental phenotypes. 
Table 2: Prevalence of psychiatric disorder and childhood outcomes in ND-CNV carriers and controls

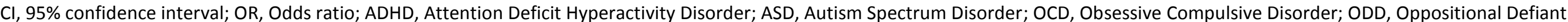

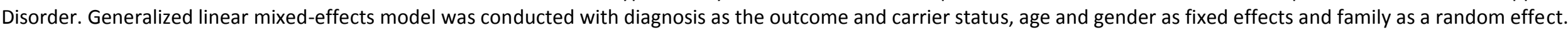

\#due to 0 values for controls OR could not be estimated, $p$-values were estimated using fishers exact test but should be treated cautiously

*Survives Benjamini-Hochberg false discovery rate 0.05 correction

\begin{tabular}{|c|c|c|c|c|c|c|c|c|c|c|}
\hline \multirow{3}{*}{ Psychiatric diagnosis } & \multicolumn{3}{|c|}{ ND-CNV carriers } & \multicolumn{3}{|c|}{ Controls } & \multicolumn{4}{|c|}{ ND- CNV carriers vs controls } \\
\hline & $\mathrm{N}(\%)$ & \multicolumn{2}{|c|}{$\% \mathrm{Cl}$} & $\mathrm{N}(\%)$ & \multicolumn{2}{|c|}{$\% \mathrm{Cl}$} & \multirow{2}{*}{$p$-value } & \multirow[t]{2}{*}{$\mathrm{OR}$} & \multicolumn{2}{|c|}{$\mathrm{Cl}$} \\
\hline & & & & & & & & & & \\
\hline Any Psychiatric Disorder & $186(79.8 \%)$ & 74.7 & 85.0 & $16(21.3 \%)$ & 12.1 & 30.6 & $7.79 \times 10^{-7} *$ & 13.8 & 7.2 & 26.3 \\
\hline ADHD & $110(47.2 \%)$ & 40.8 & 53.6 & $8(11.0 \%)$ & 3.7 & 17.7 & $2.09 \times 10^{-6} *$ & 6.9 & 3.2 & 15.1 \\
\hline Any Anxiety Disorder & $51(21.9 \%)$ & 16.6 & 27.2 & $7(9.3 \%)$ & 2.7 & 27.5 & $1.46 \times 10^{-2} *$ & 2.9 & 1.2 & 6.7 \\
\hline Any Mood Disorder & $4(1.7 \%)$ & 0.0 & 3.4 & $1(1.3 \%)$ & -1.3 & 4.0 & $7.27 \times 10^{-1}$ & 1.5 & 0.2 & 14.0 \\
\hline Any Psychotic Disorder & $0(0.0 \%)$ & - & - & $0(0.0 \%)$ & - & - & - & - & - & - \\
\hline Subthreshold psychosis & $16(6.6 \%)$ & 4.1 & 10.4 & $1(1.2 \%)$ & 0.2 & 6.5 & $6.84 \times 10^{-2}$ & 6.7 & 0.9 & 52.2 \\
\hline ASD & $150(66.1 \%)$ & 59.9 & 72.2 & $4(4.7 \%)$ & 0.0 & 9.1 & $2.50 \times 10^{-9} *$ & 44.1 & 15.3 & 127.5 \\
\hline OCD & $8(3.4 \%)$ & 1.8 & 6.6 & $0(0.0 \%)$ & - & - & $2.06 \times 10^{-1} \#$ & - & - & - \\
\hline ODD & $48(20.6 \%)$ & 15.4 & 25.8 & $5(6.7 \%)$ & 1.0 & 12.3 & $1.20 \times 10^{-2} *$ & 3.6 & 1.4 & 9.4 \\
\hline Tic Disorders & $38(16.3 \%)$ & 12.1 & 21.6 & $0(0.0 \%)$ & - & - & $2.19 \times 10^{-5} * \#$ & - & - & - \\
\hline
\end{tabular}


bioRxiv preprint first posted online Jan. 31, 2019; doi: http://dx.doi.org/10.1101/535708. The copyright holder for this preprint (which was not peer-reviewed) is the author/funder, who has granted bioRxiv a license to display the preprint in perpetuity.

It is made available under a CC-BY 4.0 International license.

Table 3: Quantitative cognitive and behavioural traits in controls and ND-CNV carriers

FSIQ, Full Scale Intelligence Quotient; PIQ, Performance Intelligence Quotient; VIQ, Verbal Intelligence Quotient; CAPA, Child and Adolescent Psychiatric Assessment; ADHD, Attention Deficit Hyperactivity Disorder; OCD, Obsessive Compulsive Disorder; ODD, Oppositional Defiant Disorder; ASD, Autism Spectrum Disorder; SDQ, Strengths and Difficulties Questionnaire. Test scores were standardised into $z$ scores using the means and SDs of the control group as reference and adjusted for age and gender, and were constructed so that a negative score denoted a poorer outcome. Linear mixed-effects models were conducted with test score as the outcome and carrier status, age and gender as fixed effects and family as a random effect. Cohen's d represents the standardised difference in trait score between ND-CNV carriers and controls adjusted for age and gender, scores were categorised into effect size descriptor categories; 0.00-0.19 negligible, 0.20-0.49 small, 0.50-0.79 medium, 0.80+ large.

\# denotes composite scores.

*Survives Benjamini-Hochberg false discovery rate 0.05 correction 
bioRxiv preprint first posted online Jan. 31, 2019; doi: http://dx.doi.org/10.1101/535708. The copyright holder for this preprint

(which was not peer-reviewed) is the author/funder, who has granted bioRxiv a license to display the preprint in perpetuity.

It is made available under a CC-BY 4.0 International license.

\begin{tabular}{|c|c|c|c|c|c|c|c|c|c|c|c|c|}
\hline \multirow[b]{2}{*}{ Trait } & \multicolumn{4}{|c|}{ ND-CNV carriers } & \multicolumn{5}{|c|}{ Controls } & \multicolumn{3}{|c|}{ Group difference } \\
\hline & $\mathbf{N}$ & $z$ & $95 \% \mathrm{Cl}$ & SD & $\mathbf{N}$ & $z$ & $95 \%$ & $\% \mathrm{Cl}$ & SD & d & $95 \% \mathrm{Cl}$ & Descriptor \\
\hline \multicolumn{13}{|l|}{ COGNITION } \\
\hline $\mathrm{FSIQ}^{\#}$ & 237 & -1.48 & $-1.64-1.33$ & 1.20 & 100 & 0.00 & -0.20 & 0.20 & 1.00 & $<1.00 \times 10^{-15 *} 1.30$ & 1.041 .56 & Large \\
\hline $\mathrm{PIQ}^{\#}$ & 238 & -1.05 & $-1.18-0.91$ & 1.05 & 99 & 0.00 & -0.20 & 0.20 & 1.00 & $<1.00 \times 10^{-15 *} 1.01$ & 0.761 .26 & Large \\
\hline $\mathrm{VIQ}^{\#}$ & 239 & -1.43 & $-1.58-1.28$ & 1.18 & 100 & 0.00 & -0.20 & 0.20 & 1.00 & $<1.00 \times 10^{-15 *} 1.26$ & 1.001 .52 & Large \\
\hline Non-verbal reasoning & 238 & -1.01 & $-1.16-0.87$ & 1.14 & 100 & 0.00 & -0.20 & 0.20 & 1.00 & $<1.00 \times 10^{-15 *} 0.93$ & 0.681 .17 & Large \\
\hline Perceptual organisation & 237 & -0.84 & $-0.96-0.71$ & 0.98 & 99 & 0.00 & -0.20 & 0.20 & 1.00 & $3.49 \times 10^{-14} * 0.85$ & 0.601 .10 & Large \\
\hline Verbal knowledge & 237 & -1.24 & $-1.38-1.11$ & 1.04 & 100 & 0.00 & -0.20 & 0.20 & 1.00 & $<1.00 \times 10^{-15 *} 1.22$ & 0.961 .47 & Large \\
\hline Verbal reasoning & 238 & -1.21 & $-1.37-1.06$ & 1.20 & 100 & 0.00 & -0.20 & 0.20 & 1.00 & $<1.00 \times 10^{-15 *} 1.07$ & 0.811 .32 & Large \\
\hline Set-shifting & 198 & -0.72 & $-0.89-0.56$ & 1.14 & 87 & 0.00 & -0.21 & 0.21 & 1.00 & $5.99 \times 10^{-10} * 0.66$ & 0.400 .92 & Medium \\
\hline Spatial working memory & 212 & -0.81 & $-0.96-0.66$ & 1.09 & 64 & 0.00 & -0.25 & 0.25 & 1.00 & $6.50 \times 10^{-08} * 0.76$ & 0.471 .05 & Medium \\
\hline Spatial planning & 170 & -0.58 & $-0.72-0.44$ & 0.94 & 60 & 0.00 & -0.26 & 0.26 & 1.00 & $4.08 \times 10^{-05} * 0.61$ & 0.310 .91 & Medium \\
\hline Sustained attention & 155 & -1.01 & $-1.21-0.80$ & 1.27 & 57 & 0.00 & -0.27 & 0.27 & 1.00 & $4.55 \times 10^{-08 * 0.84}$ & 0.521 .16 & Large \\
\hline Processing speed & 194 & -0.39 & $-0.54-0.24$ & 1.09 & 62 & 0.00 & -0.25 & 0.25 & 1.00 & $8.95 \times 10^{-03 *} 0.37$ & 0.080 .66 & Small \\
\hline \multicolumn{13}{|l|}{ PSYCHIATRIC TRAITS } \\
\hline Total CAPA symptom count ${ }^{\#}$ & 233 & -1.23 & $-1.38-1.08$ & 1.18 & 75 & 0.00 & -0.23 & 0.23 & 1.00 & $<1.00 \times 10^{-15 *} 1.09$ & 0.811 .36 & Large \\
\hline Anxiety CAPA subscale & 233 & -0.85 & $-1.04-0.67$ & 1.45 & 75 & 0.00 & -0.23 & 0.23 & 1.00 & $1.00 \times 10^{-06} * 0.63$ & 0.370 .90 & Medium \\
\hline ADHD CAPA subscale & 233 & -1.20 & $-1.36-1.04$ & 1.23 & 75 & 0.00 & -0.23 & 0.23 & 1.00 & $1.82 \times 10^{-14} * 1.02$ & 0.741 .30 & Large \\
\hline Mood CAPA subscale & 233 & $3-0.60$ & $-0.74-0.45$ & 1.14 & 75 & 0.00 & -0.23 & 0.23 & 1.00 & $4.43 \times 10^{-5} * 0.54$ & 0.270 .80 & Medium \\
\hline OCD CAPA subscale & 233 & -0.67 & $-0.92-0.43$ & 1.88 & 75 & 0.00 & -0.23 & 0.23 & 1.00 & $1.30 \times 10^{-3} * 0.40$ & 0.130 .66 & Small \\
\hline ODD CAPA subscale & 233 & -0.71 & $-0.87-0.56$ & 1.17 & 75 & 0.00 & -0.23 & 0.23 & 1.00 & $4.36 \times 10^{-6} * 0.63$ & 0.370 .90 & Medium \\
\hline Sleep CAPA subscale & 233 & $3-0.69$ & $-0.86-0.52$ & 1.33 & 75 & 0.00 & -0.23 & 0.23 & 1.00 & $3.45 \times 10^{-5} * 0.55$ & 0.280 .81 & Medium \\
\hline Subclinical psychotic experiences (child CAPA) & 244 & -0.55 & $-0.84-0.27$ & 2.27 & 83 & 0.00 & -0.22 & 0.22 & 1.00 & $2.97 \times 10^{-2} * 0.27$ & 0.020 .52 & Small \\
\hline \multicolumn{13}{|l|}{ FUNCTIONING } \\
\hline General functioning & 138 & $3-1.36$ & $-1.52-1.20$ & 0.96 & 56 & 0.00 & -0.27 & 0.27 & 1.00 & $<1.00 \times 10^{-15 *} 1.40$ & 1.051 .75 & Large \\
\hline Social functioning & 128 & $3-1.60$ & $-1.77-1.42$ & 1.01 & 56 & 0.00 & -0.27 & 0.27 & 1.00 & $<1.00 \times 10^{-15 *} 1.60$ & 1.221 .96 & Large \\
\hline \multicolumn{13}{|l|}{ PSYCHOPATHOLOGY } \\
\hline ASD traits & 227 & -2.21 & $-2.40-2.03$ & 1.39 & 86 & 0.00 & -0.21 & 0.21 & 1.00 & $<1.00 \times 10^{-15 *} 1.71$ & 1.422 .01 & Large \\
\hline Motor coordination & 226 & -1.89 & $-2.05-1.73$ & 1.23 & 86 & 0.00 & -0.21 & 0.21 & 1.00 & $<1.00 \times 10^{-15 *} 1.62$ & 1.331 .91 & Large \\
\hline SDQ total (caregiver report) & 229 & -1.59 & $-1.72-1.45$ & 1.05 & 88 & 0.00 & -0.21 & 0.21 & 1.00 & $<1.00 \times 10^{-15} * 1.54$ & 1.251 .82 & Large \\
\hline Conduct SDQ subscale (caregiver report) & 229 & -0.60 & $-0.74-0.46$ & 1.09 & 88 & 0.00 & -0.21 & 0.21 & 1.00 & $4.97 \times 10^{-6} * 0.57$ & 0.320 .82 & Medium \\
\hline Emotional SDQ subscale (caregiver report) & 229 & -0.79 & $-0.93-0.65$ & 1.06 & 88 & 0.00 & -0.21 & 0.21 & 1.00 & $7.83 \times 10^{-10} * 0.76$ & 0.501 .01 & Medium \\
\hline Hyperactivity SDQ subscale (caregiver report) & 229 & -2.27 & $-2.45-2.09$ & 1.39 & 88 & 0.00 & -0.21 & 0.21 & 1.00 & $<1.00 \times 10^{-15 *} 1.76$ & 1.462 .05 & Large \\
\hline Peer SDQ subscale (caregiver report) & 229 & -1.39 & $-1.54-1.24$ & 1.14 & 88 & 0.00 & -0.21 & 0.21 & 1.00 & $<1.00 \times 10^{-15 *} 1.27$ & 0.991 .54 & Large \\
\hline Prosocial SDQ subscale (caregiver report) & 229 & -0.87 & $-1.02-0.73$ & 1.09 & 88 & 0.00 & -0.21 & 0.21 & 1.00 & $1.56 \times 10^{-11} * 0.82$ & 0.561 .08 & Large \\
\hline SDQ total (teacher report) ${ }^{\#}$ & 138 & -1.06 & $-1.23-0.90$ & 0.99 & 52 & 0.00 & -0.28 & 0.28 & 1.00 & $1.36 \times 10^{-11 *} 1.08$ & 0.731 .42 & Large \\
\hline Conduct SDQ subscale (teacher report) & 138 & -0.45 & $-0.65-0.25$ & 1.17 & 52 & 0.00 & -0.28 & 0.28 & 1.00 & $1.31 \times 10^{-2} * 0.40$ & 0.080 .72 & Small \\
\hline Emotional SDQ subscale (teacher report) & 138 & -0.53 & $-0.69-0.37$ & 0.97 & 52 & 0.00 & -0.28 & 0.28 & 1.00 & $7.54 \times 10^{-4} * 0.54$ & 0.220 .87 & Medium \\
\hline Hyperactivity SDQ subscale (teacher report) & 138 & -1.36 & $-1.61-1.12$ & 1.45 & 52 & 0.00 & -0.28 & 0.28 & 1.00 & $1.84 \times 10^{-10 *} 1.02$ & 0.671 .36 & Large \\
\hline Peer SDQ subscale (teacher report) & 138 & -0.86 & $-1.06-0.66$ & 1.18 & 52 & 0.00 & -0.28 & 0.28 & 1.00 & $1.96 \times 10^{-6} * 0.76$ & 0.431 .09 & Medium \\
\hline Prosocial SDQ subscale (teacher report) & 138 & -0.96 & $-1.19-0.73$ & 1.37 & 52 & 0.00 & -0.28 & 0.28 & 1.00 & $2.30 \times 10^{-6 *} 0.76$ & 0.421 .09 & Medium \\
\hline
\end{tabular}


bioRxiv preprint first posted online Jan. 31, 2019; doi: http://dx.doi.org/10.1101/535708. The copyright holder for this preprint

(which was not peer-reviewed) is the author/funder, who has granted bioRxiv a license to display the preprint in perpetuity.

It is made available under a CC-BY 4.0 International license.

Table 4: Effect size of genotype, age, and gender on phenotypic outcomes.

Eta, eta-squared, FSIQ, Full Scale Intelligence Quotient; PIQ, Performance Intelligence Quotient; VIQ, Verbal Intelligence Quotient; CAPA, Child and Adolescent Psychiatric Assessment; ADHD, Attention Deficit Hyperactivity Disorder; OCD, Obsessive Compulsive Disorder; ODD, Oppositional Defiant Disorder; ASD, Autism Spectrum Disorder; SDQ, Strengths and Difficulties Questionnaire. P-values, eta-squared values were derived from ANCOVA analysis examining the effect of genotype, age and gender. Standardised beta values were derived from linear regression models. For gender a positive beta value indicated that males had a higher score compared to females, for age a positive beta value indicated that the score increased with age.

\# denotes composite scores.

*Survives Benjamini-Hochberg false discovery rate 0.05 correction 
bioRxiv preprint first posted online Jan. 31, 2019; doi: http://dx.doi.org/10.1101/535708. The copyright holder for this preprint (which was not peer-reviewed) is the author/funder, who has granted bioRxiv a license to display the preprint in perpetuity.

It is made available under a CC-BY 4.0 International license.

\begin{tabular}{|c|c|c|c|c|c|c|c|c|}
\hline \multirow{2}{*}{ Trait } & \multicolumn{2}{|c|}{ Genotype } & \multicolumn{3}{|c|}{ Gender } & \multicolumn{3}{|c|}{ Age } \\
\hline & Eta \% & $p$ & Eta \% & Beta & p & Eta \% & Beta & $p$ \\
\hline \multicolumn{9}{|l|}{ COGNITION } \\
\hline $\mathrm{FSIQ}^{\#}$ & 18.5 & $2.37 \times 10^{-6} *$ & 1.3 & -0.10 & $5.71 \times 10^{-2}$ & 3.0 & -0.18 & $3.61 \times 10^{-3}$ \\
\hline $\mathrm{PIQ}^{\#}$ & 19.4 & $6.03 \times 10^{-7} *$ & 1.4 & -0.10 & $4.38 \times 10^{-2}$ & 3.7 & -0.20 & $1.09 \times 10^{-3} *$ \\
\hline $\mathrm{VIO}^{\#}$ & 13.8 & $5.00 \times 10^{-4} *$ & 0.5 & -0.06 & $2.49 \times 10^{-1}$ & 1.9 & -0.14 & $2.34 \times 10^{-2}$ \\
\hline Non-verbal reasoning & 18.2 & $2.15 \times 10^{-6} *$ & 0.2 & -0.03 & $3.97 \times 10^{-1}$ & 5.3 & -0.24 & $1.02 \times 10^{-4}$ \\
\hline Perceptual organisation & 15.5 & $7.62 \times 10^{-5} *$ & 2.8 & -0.16 & $6.37 \times 10^{-3} *$ & 1.3 & -0.12 & $6.39 \times 10^{-2}$ \\
\hline Verbal knowledge & 10.7 & $1.03 \times 10^{-2} *$ & 0.7 & -0.07 & $1.84 \times 10^{-1}$ & 1.2 & -0.12 & $7.76 \times 10^{-2}$ \\
\hline Verbal reasoning & 10.9 & $8.37 \times 10^{-3} *$ & 0.3 & -0.04 & $3.77 \times 10^{-1}$ & 1.5 & -0.13 & $5.20 \times 10^{-2}$ \\
\hline Set-shifting & 7.6 & $2.09 \times 10^{-1}$ & 1.8 & -0.15 & $5.09 \times 10^{-2}$ & 3.0 & 0.18 & $1.32 \times 10^{-2} *$ \\
\hline Spatial working memory & 9.0 & $7.25 \times 10^{-2}$ & 0.4 & -0.04 & $3.46 \times 10^{-1}$ & 3.2 & -0.19 & $7.92 \times 10^{-3}$ \\
\hline Spatial planning & 14.3 & $1.34 \times 10^{-2} *$ & 0.4 & 0.09 & $3.84 \times 10^{-1}$ & 2.1 & -0.15 & $5.17 \times 10^{-2}$ \\
\hline Sustained attention & 5.4 & $4.93 \times 10^{-1}$ & 3.8 & 0.18 & $5.35 \times 10^{-3} *$ & 25.1 & 0.53 & $1.89 \times 10^{-11}$ \\
\hline Processing speed & 15.7 & $1.44 \times 10^{-3} *$ & 0.6 & -0.09 & $2.52 \times 10^{-1}$ & 0.9 & 0.10 & $1.67 \times 10^{-1}$ \\
\hline \multicolumn{9}{|l|}{ PSYCHIATRIC TRAITS } \\
\hline Total CAPA symptom count ${ }^{\#}$ & 19.0 & $3.89 \times 10^{-6} *$ & 1.0 & 0.10 & $1.07 \times 10^{-1}$ & 0.1 & -0.03 & $6.54 \times 10^{-1}$ \\
\hline Anxiety CAPA subscale & 14.4 & $5.35 \times 10^{-4} *$ & 0.0 & 0.03 & $7.28 \times 10^{-1}$ & 0.1 & -0.04 & $5.76 \times 10^{-1}$ \\
\hline ADHD CAPA subscale & 14.5 & $3.43 \times 10^{-4} *$ & 1.1 & 0.10 & $9.18 \times 10^{-2}$ & 1.1 & 0.11 & $9.13 \times 10^{-2}$ \\
\hline Mood CAPA subscale & 9.8 & $2.26 \times 10^{-2}$ & 0.3 & 0.07 & $4.24 \times 10^{-1}$ & 2.7 & -0.17 & $1.05 \times 10^{-2}$ \\
\hline OCD CAPA subscale & 6.0 & $2.80 \times 10^{-1}$ & 1.5 & 0.14 & $5.65 \times 10^{-2}$ & 1.3 & -0.12 & $7.43 \times 10^{-2}$ \\
\hline ODD CAPA subscale & 15.7 & $1.44 \times 10^{-4} *$ & 0.1 & -0.03 & $6.13 \times 10^{-1}$ & 0.1 & -0.04 & $5.70 \times 10^{-1}$ \\
\hline Sleep CAPA subscale & 5.1 & $4.40 \times 10^{-1}$ & 2.4 & 0.16 & $1.83 \times 10^{-2} *$ & 0.0 & -0.01 & $8.86 \times 10^{-1}$ \\
\hline Subclinical psychotic experiences (child CAPA) & 11.9 & $2.05 \times 10^{-3} *$ & 0.1 & 0.06 & $5.85 \times 10^{-1}$ & 3.8 & -0.20 & $1.4 \times 10^{-3} \quad *$ \\
\hline \multicolumn{9}{|l|}{ FUNCTIONING } \\
\hline General functioning & 16.2 & $2.82 \times 10^{-2}$ & 1.1 & 0.11 & $2.11 \times 10^{-1}$ & 0.0 & 0.01 & $9.01 \times 10^{-1}$ \\
\hline Social functioning & 19.7 & $1.00 \times 10^{-2} *$ & 1.1 & 0.11 & $2.17 \times 10^{-1}$ & 0.0 & 0.02 & $8.27 \times 10^{-1}$ \\
\hline \multicolumn{9}{|l|}{ PSYCHOPATHOLOGY } \\
\hline ASD traits & 11.6 & $7.39 \times 10^{-3} *$ & 0.7 & 0.09 & $2.08 \times 10^{-1}$ & 0.6 & -0.08 & $2.34 \times 10^{-1}$ \\
\hline Motor coordination & 11.3 & $9.81 \times 10^{-3} *$ & 1.7 & 0.13 & $4.61 \times 10^{-2}$ & 0.0 & 0.02 & $7.63 \times 10^{-1}$ \\
\hline SDQ total (caregiver report) ${ }^{\#}$ & 18.4 & $1.20 \times 10^{-5} *$ & 0.0 & 0.02 & $8.77 \times 10^{-1}$ & 0.4 & -0.06 & $3.19 \times 10^{-1}$ \\
\hline Conduct SDQ subscale (caregiver report) & 17.5 & $3.19 \times 10^{-5} *$ & 0.2 & -0.05 & $4.25 \times 10^{-1}$ & 0.0 & 0.00 & $9.39 \times 10^{-1}$ \\
\hline Emotional SDQ subscale (caregiver report) & 9.2 & $4.24 \times 10^{-2}$ & 0.6 & -0.07 & $2.19 \times 10^{-1}$ & 1.1 & -0.11 & $9.93 \times 10^{-2}$ \\
\hline Hyperactivity SDQ subscale (caregiver report) & 13.6 & $6.64 \times 10^{-4} *$ & 2.2 & 0.13 & $1.61 \times 10^{-2} *$ & 3.0 & 0.18 & $5.04 \times 10^{-3}$ \\
\hline Peer SDQ subscale (caregiver report) & 7.9 & $9.35 \times 10^{-2}$ & 0.0 & 0.04 & $7.71 \times 10^{-1}$ & 4.3 & -0.21 & $1.34 \times 10^{-3} *$ \\
\hline Prosocial SDQ subscale (caregiver report) & 11.9 & $4.88 \times 10^{-3} *$ & 1.8 & 0.14 & $3.72 \times 10^{-2}$ & 0.0 & -0.01 & $8.75 \times 10^{-1}$ \\
\hline
\end{tabular}


Figure 1: Visual representation of models of genotype-phenotype relationships

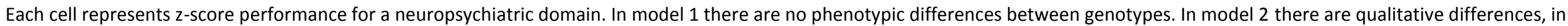

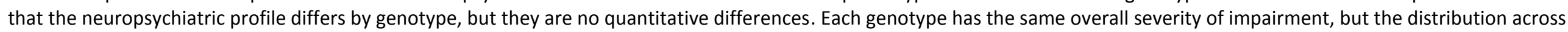

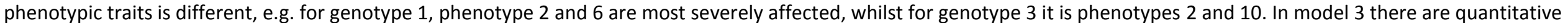

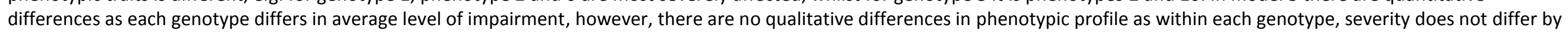
phenotype. In model 4 there are both quantitative and qualitative differences in neuropsychiatric profile.

Model 1: No genotype-phenotype relationship
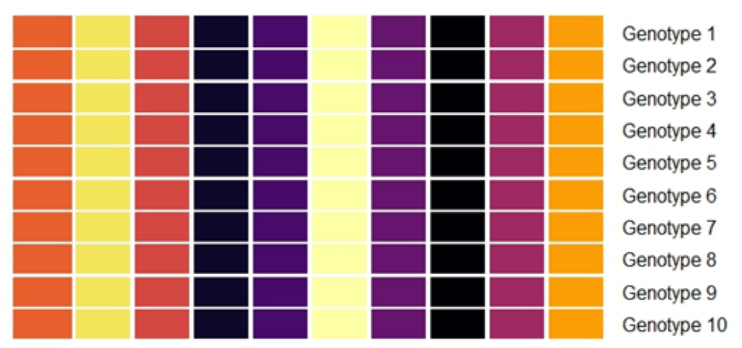

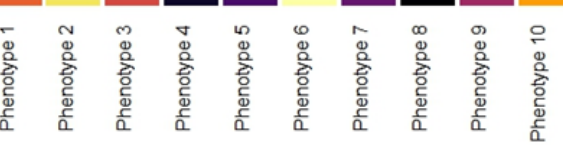

Model 3: Quantitative differences

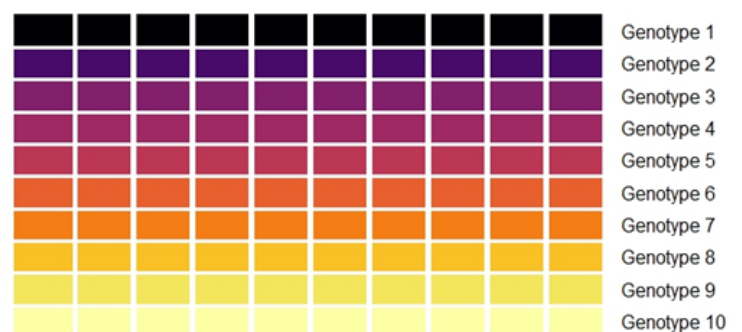

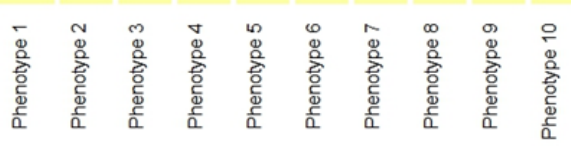

Model 2: Qualitative differences
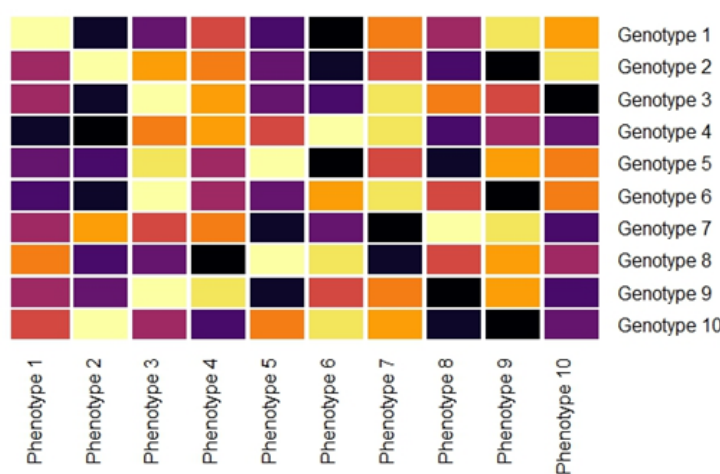

Model 4: Qualitative and Quantitative differences

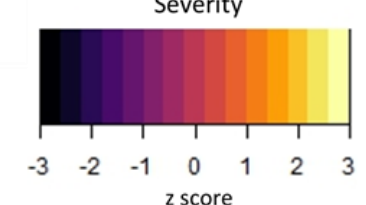

z score

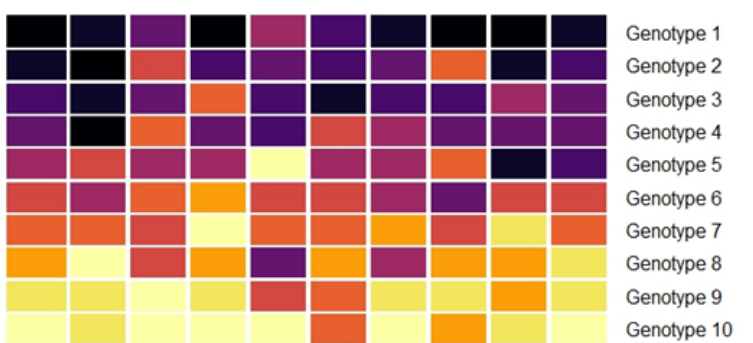

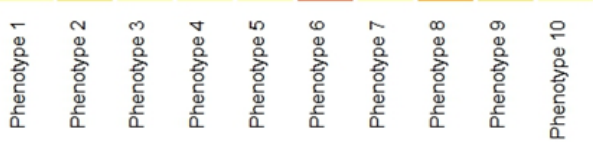


Figure 2: Standardised difference between ND-CNV carriers and controls on quantitative cognitive and behavioural traits

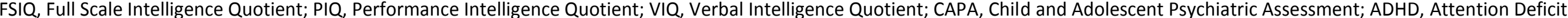

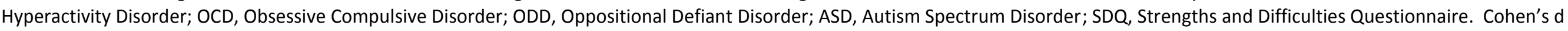

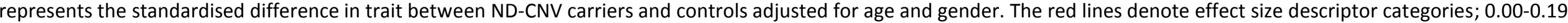
negligible, 0.20-0.49 small, 0.50-0.79 medium, 0.80+ large.

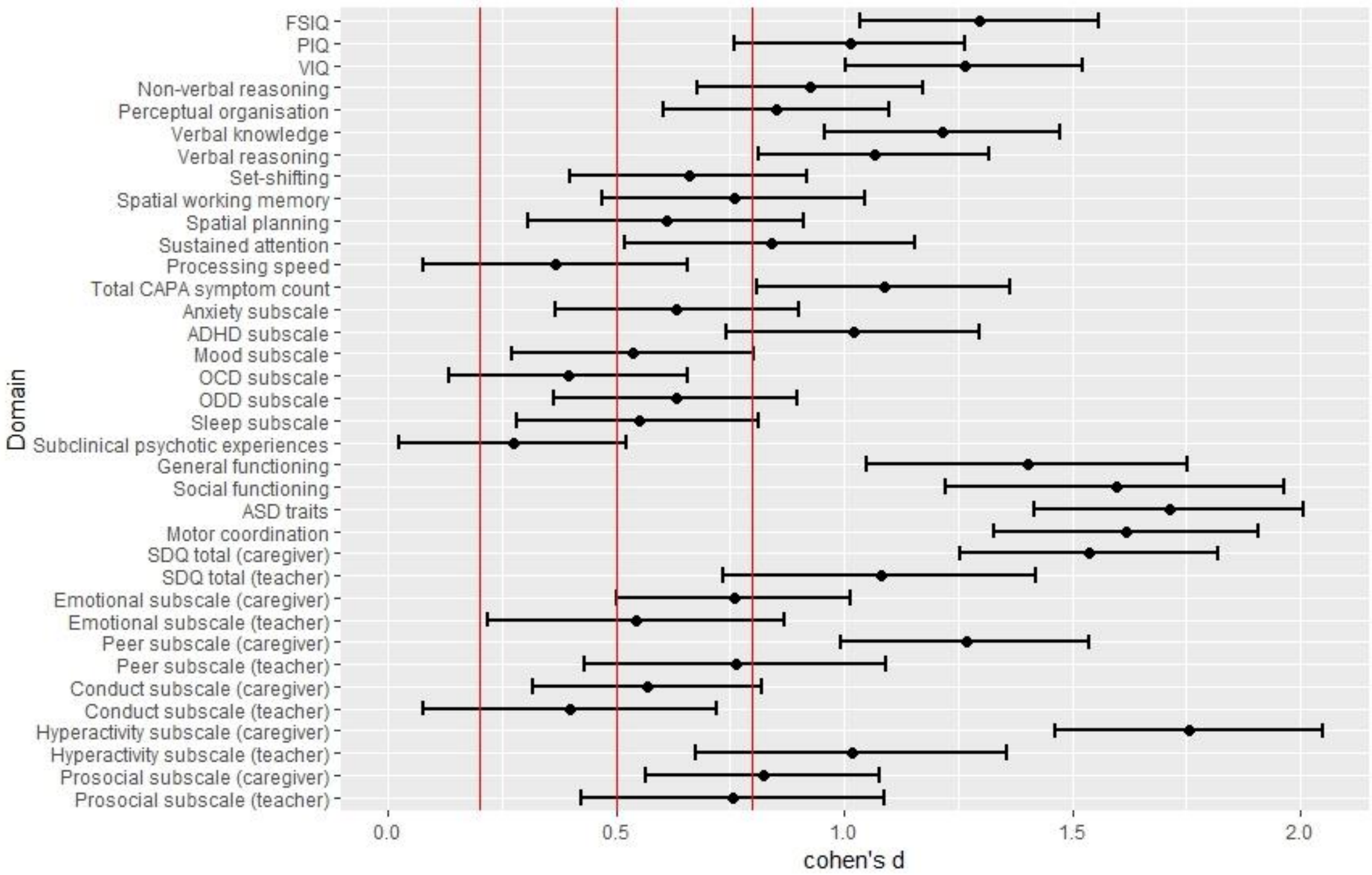


Figure 3: Phenotypic profiles of individual ND-CNV genotypes

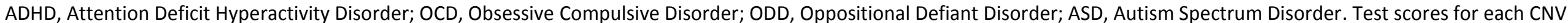

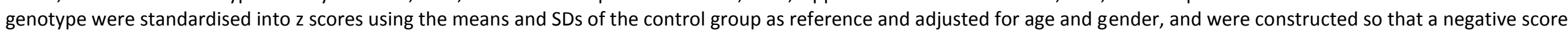

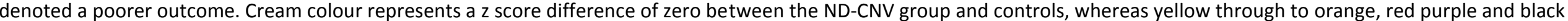

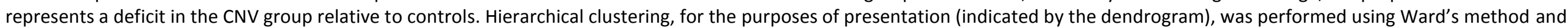
Euclidian distance. Domains clustered into two groups; mental health and cognitive comorbidities (cluster A, blue box) and neurodevelopmental traits (cluster B, green box)
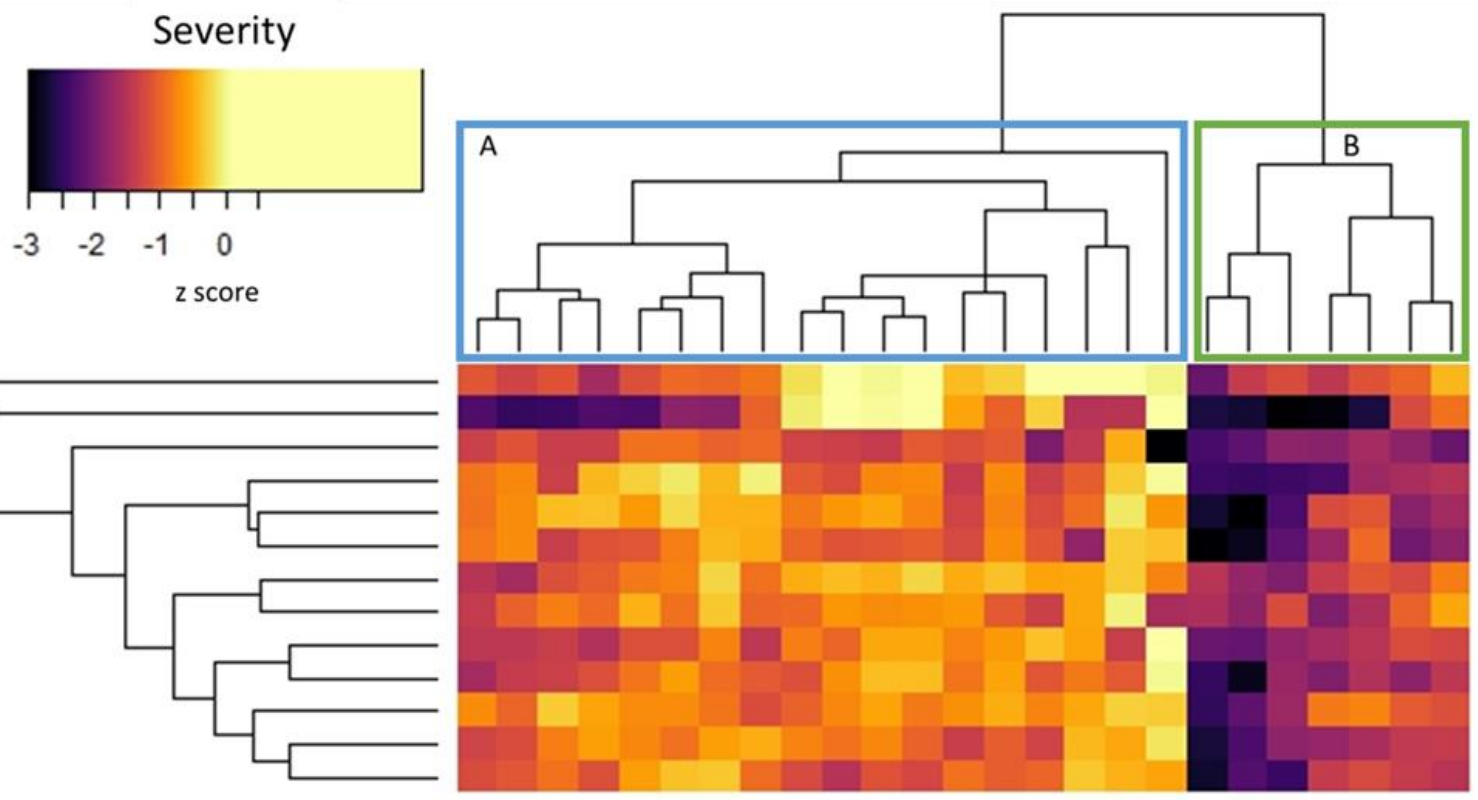

\section{$22 \mathrm{~g} 11.2$ deletion}

$16 \mathrm{p} 11.2$ proximal duplication

$15 \mathrm{~g} 13.3$ duplication

1 221.1 distal duplication

16 p11.2 distal deletion

$16 \mathrm{p} 11.2$ proximal deletion

$15 \mathrm{q} 13.3$ deletion

$2 \mathrm{p} 16.3$ deletion

22q11.2 duplication

$15 \mathrm{~g} 11.2$ deletion

$1 \mathrm{q} 21.1$ distal deletion

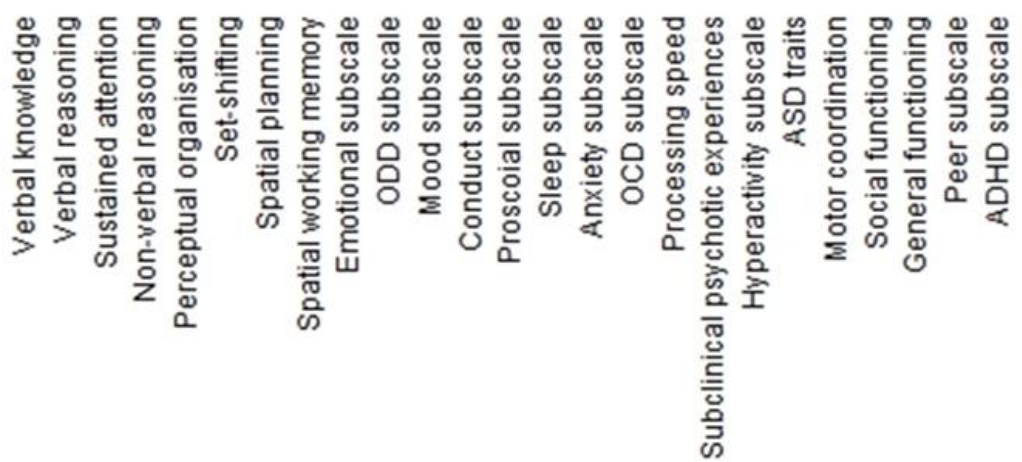

